Antonella Mallozzi

The Graduate Center - CUNY

\title{
Putting Modal Metaphysics First ${ }^{1}$ \\ From Knowledge of Essence to Knowledge of Metaphysical Necessity
}

*Forthcoming in Synthese, penultimate draft*

\begin{abstract}
I propose that we approach the epistemology of modality by putting modal metaphysics first and, specifically, by investigating the metaphysics of essence. Following a prominent Neo-Aristotelian view, I hold that metaphysical necessity depends on the nature of things, namely their essences. I further clarify that essences are core properties having distinctive superexplanatory powers. In the case of natural kinds, which is my focus in the paper, superexplanatoriness is due to the fact that the essence of a kind is what causes all the many properties and behaviors that are typically shared by all the instances of the kind. Accordingly, we know what is necessarily true of kinds by knowing what is essential to them in the sense of actually playing such causal-explanatory roles. Modal reasoning aimed at discovering metaphysical necessity thus proceeds via essentialist deduction: we move from essentialist truths to reach necessary truths.
\end{abstract}

\section{Introduction}

I recommend approaching the epistemology of modality by putting modal metaphysics first. In order to elucidate knowledge of modality, we should first have a good grip on what this knowledge is about. For we cannot hope to explain how we know the truths of a given domain without some conception of what constitutes the truths of that domain. (My focus here is metaphysical modality, but an analogous point can be made for logical modality, physical modality, and so on). Putting modal metaphysics first means prioritizing questions concerning the proper domain and scope of metaphysical modality, and what grounds this kind of modal truth as opposed to other modalities.

More precisely, this is an essence-first approach to modal knowledge. Following a prominent Neo-Aristotelian view, I hold that the metaphysically necessary truths depend on truths about essences. There is a distinctive source of metaphysical necessity, which is located in the nature of thingsspecifically, in their essential properties. Accordingly, knowledge of necessity should be understood primarily in terms of essentialist knowledge. Metaphysical investigation guides us to formulate principled criteria for modal knowledge based on essentialist truth.

\footnotetext{
${ }^{1}$ Inspired by the title of Michael Devitt's book Putting Metaphysics First, Oxford: OUP (2010).
} 
Typical cases of metaphysical necessities (after Kripke's Naming and Necessity) include fundamental kind membership, individuals' origins, the constitution of particulars, and certain cases of the necessity of identity. In this paper I focus on the necessities involving natural kinds. ${ }^{2}$ Chemical, biological, geological, physical, and even astrophysical kinds are all good examples. So, for instance, the metal silver could not have had a different atomic number than the one it actually has, though it probably might have been blue and dull, rather than white and shiny. These are metaphysical modal claims which, I maintain, depend on facts about essence. But what is the essence or nature of a natural kind?

My thesis is that essences have special explanatory powers for natural kinds - indeed, they are superexplanatory for the many properties and behaviors that are typically shared by all the instances of a kind.

In philosophy of science, many agree that natural kinds are causally grounded. There is an underlying property or set of properties, or a mechanism, which causes the many properties and behaviors that are typically shared by all the instances of a kind. That crucially explains what is sometimes called the "epistemic fertility" of natural kinds: namely, the fact that they support a wide set of scientific practices including inductive, taxonomic, and explanatory practices. My proposal is that this underlying causal core, or mechanism, is the essence of a natural kind. Essences cause the many properties and behaviors that typically characterize all the instances of a kind, and that is why they are in turn superexplanatory with respect to all such instances.

We thus have a better grip on what it is about the nature or identity of a kind that determines modal implications; or what roles essence plays for the modal profiles of the instances of natural kindsparticularly, for their necessary properties.

If this metaphysical story is correct, the modal epistemology of a wide range of cases is simpler than many have supposed. Essentialist knowledge is within our reach; actually, it is largely available to us already. For in many cases essentialist knowledge is empirical, scientific knowledge about the fundamental nature of kinds, particularly about their causal structure. Understanding what is necessarily true of silver is a function of understanding what is essential to silver, in the sense of actually playing the relevant causal-explanatory role for all the instances of this element. More generally, reasoning aimed at

\footnotetext{
${ }^{2}$ For a discussion of other typical cases of metaphysical necessities, see Godman, Mallozzi, and Papineau: "Essential Properties are Super-Explanatory. Taming Metaphysical Modality" (ms.)
} 
grasping metaphysical necessity proceeds via essentialist deduction: we move from essentialist truths to reach necessary truths.

\section{The Plan}

In section 1, I explain the modal metaphysics-first approach and situate it within the broader debate. In section 2, I lay out what I call a "constitutive" notion of essence in line with the NeoAristotelian notion promoted by Fine and introduce a basic Kripkean bridge-principle for knowledge of necessity. In section 3, I propose that, in the case of natural kinds, such an essence or nature is characterized by distinctive causal and explanatory powers for the occurrence of all the properties typically shared by the instances of a kind. In section 4, I say more about the causal and explanatory powers of essence and address a few objections. In section 5, I explain how the Kripkean basic bridgeprinciple captures the metaphysical relationship between essence and necessity and guides modal inference accordingly. In section 6, I take stock and make some conclusive remarks.

\section{Switching the Focus. Why Modal Metaphysics First}

Putting modal metaphysics first means elucidating the subject matter of modal knowledge as the basis to elucidate how we gain modal knowledge. The project might thus be seen broadly as a contribution to the attempt to meet, in the area of metaphysical modality, Christopher Peacocke's Integration Challenge: namely, "the general task of providing, for any given area, a simultaneously acceptable metaphysics and epistemology" (1999: 1). Moreover, while discussing the nature of $x$ before addressing the issue of how we know about $x$ is generally a profitable methodology (because an answer to the latter issue largely depends on what $x$ is), we see additional advantages in the case of metaphysical necessity. For we learn from the modal metaphysics that the epistemology of modality depends on the epistemology of essence.

What I am recommending is in a way a return to modal metaphysics. The epistemology of modality of the past two decades or so (starting perhaps with van Inwagen's 1998 seminal paper) might be seen as a whole as a response to much philosophy of modality up to that point, which had focused instead mostly on modal metaphysics. (Think of the enormous literature following the developments in modal logic in the 1960s and 1970s, and the many issues concerning possible worlds, their ontology, and the conditions for individual transworld identity in particular. Think of the work of Kripke and Lewis, and of all those who built off of their work throughout the 1980s). In the face of so much modal metaphysics, 
it then seemed natural to turn to the central question of how we know, or form justified beliefs about, such modal matters, and to the investigation of modal and counterfactual reasoning.

The dominant approach in the past twenty years has indeed focused on the analysis of the proper means (i.e., the methods, or cognitive-psychological processes) that we use in modal reasoning and in forming modal beliefs. This approach is widespread: it includes the family of so-called conceivability theories (Chalmers 2002; Yablo 1993; Menzies 1998); as well as those appealing to modal intuition (BonJour 1998; Bealer 2002; Chudnoff 2013); but also those theories variously appealing to imaginative exercises, counterfactual reasoning, and similarity reasoning (Ichikawa \& Jarvis 2011; Kung 2010; Williamson 2007; Roca-Royes 2016). These "means-first" theories, as I call them, may operate on the basis of specific notions of metaphysical possibility and necessity, and sometimes include some discussion of modal metaphysics. Accordingly, they may still be regarded as proper ways of addressing Peacocke's Integration Challenge. However, it is not one of these theories' primary aims to tackle the issue of the source of metaphysical modal truth; nor, a fortiori, to undertake the study of essence and its relationship to modality.

Some question the idea that there is something uniquely "metaphysically significant" about metaphysical necessity (Clarke-Doane 2017). Others go further and assimilate metaphysical modality, depending on the cases, to the domain of physical modality, or logical modality, etc. (Priest "Metaphysical Necessity: A Skeptical Perspective" ms.) I will not take issue with such deflationary and skeptical views. ${ }^{3}$ There are a number of positive characterizations of "metaphysical modality" that we might consider instead. A classic reference is Naming \& Necessity, where Kripke carves out a notion that is distinct from both physical necessity and epistemic necessity ("which might just mean a priori"). He encourages us to ask ourselves: "is it possible that, in this respect, the world should have been different from the way it is?" (1980: 36. My emphasis). He further characterizes this as "absolute necessity" and "necessity tout-court", as well as "necessity in the strongest sense". Some of the Kripkean glosses are still popular in the literature (Fine 2005; Hale 2013; Kment 2014); while others have been added. For

\footnotetext{
${ }^{3}$ An even more radical challenge comes from recent forms of modal anti-realism such as Thomasson's Modal Normativism (2007) and Sidelle's Conventionalism (1989). These theorists deny that our modal language describes real facts "out there" in the world and offer non-descriptivist accounts of the meaning and function of our modal expressions. For Sidelle, modal claims are fully grounded in our linguistic conventions. For Thomasson, they express constitutive semantic rules of our language. They both think that these sorts of solutions in turn simplify the modal epistemology. Here I am granting that our modal notions track genuine modal facts - specifically, facts about essence - which are independent of the way we shape the world linguistically or conceptually. My aim is to clarify what those essentialist facts are, which in turn I also believe simplifies the modal epistemology for a wide range of cases. This is a fundamental contrast between "conventionalism" vs. "realism" about essence and modality worth exploring further (cf. Vaidya 2017). (Thanks to an anonymous referee for pushing me on this issue).
} 
example, some classify metaphysical modality within the category of the so-called "objective" modalities; in fact, as the "broadest objective modality" (Williamson 2016; Vetter 2016).

My view is that we have a grip on a notion of possibility and necessity that is both (a) different at least from matters of logical-conceptual coherence and apriority; and (b) de re in the sense of being dependent on the fundamental nature of things or their essences. I take those to be the most general, distinctive features of metaphysical modality. This characterization lines up with the notion adopted within the Neo-Aristotelian camp lead by Fine, as well as the Kripkean notion, while also being compatible with the idea that metaphysical modality has objective status.

Furthermore, a modal-metaphysics, essence-first approach helps us address what might be regarded as the central problem for modal epistemology. We need suitable constraints for modal reasoning and imaginative exercises, so as to ensure (or at least enhance the chances) that they result in true beliefs. Vaidya and Wallner call this the problem of "Modal Epistemic Friction" (in "The Epistemology of Modality and the Problem of Modal Epistemic Friction”, ms.) In order for our conceivability, counterfactual, and other imaginative exercises to reliably capture modal truth, there must be some kind of push-back, or friction, to make sure that they do not lead us astray but rather capture genuine possibility and necessity. It is thus crucial to understand what the correct constraints for each particular modal sub-field are, and in virtue of what they lead us to correct modal judgment.

I am suggesting that integrating this bit of essentialist theorizing might prove fruitful to get a better grip on the constraints for the sub-field of metaphysical modality-for those, I maintain, are a function of essentialist truth. By locating the source of metaphysical necessity in facts about the fundamental makeup of the world, my modal metaphysics-first approach secures us with principled, nonarbitrary criteria for judging modal matters. We might compare an opposite, "a priori-conceptual" approach, which instead locates the source of metaphysical necessity at the level of our modal concepts“in the rational domain", as Chalmers puts it (2010: 185). This kind of modal metaphysics instead identifies metaphysical modality with conceptual truths based on our understanding of linguistic expressions and of the notion of metaphysical necessity. Thereby, it makes metaphysical possibility a matter of (ideal) coherence, rather than of what is compatible with the nature of things. ${ }^{4}$

The broader philosophical atmosphere indicates that the project comes at an opportune moment, as we witness to an explosion of interest in modal metaphysics in the latest debates, especially the Neo-

\footnotetext{
${ }^{4}$ For more on this contrast see my (2018).
} 
Aristotelian type here defended. Moreover, it is encouraging to see that several authors have recently developed an account of modal epistemology based on essentialist knowledge, thereby endorsing a modal-metaphysics, essence-first approach of the kind I propose (examples include Hale 2013; Jago “Knowing How Things Might Have Been” ms., Lowe 2012; Oderberg 2007; Tahko forthcoming; Vaidya 2008; Vaidya and Wallner ms., cit.) However, to anticipate a little the following discussion, my account of modal knowledge differs from other essentialist accounts in the literature primarily in the way I characterize the notion of "essence". My thesis is that essences are special properties that have two distinctive features. First, they have important causal and explanatory powers for how things areindeed, they are superexplanatory properties. Second, essences are typically an object of empirical, scientific investigation.

\section{A Constitutive View of Essence}

What are essential properties? Following a prominent Neo-Aristotelian tradition lead by Fine (1994a), I hold that essential properties are not merely the necessary properties of things. We can distinguish between, on the one hand, a modalist conception of essence, for which essentialist notions simply amount to certain de re modal notions, namely metaphysically necessary properties and truths; vs. a Finean conception of essence, I call it "constitutive", for which essentialist notions rather depend on the nature or identity of things. Essential properties make a thing what it is or constitutively determine what it is to be a certain thing. A thing is the very entity it is in virtue of its essence (cf. Kment 2014; Hale 2013; Devitt 2008). Essences in this sense are also often said to be captured by Lockean real definitions, i.e., roughly, propositions that define the thing itself (as opposed to a word for the thing). ${ }^{5}$

According to the constitutive conception, essences do not merely amount to necessities, they rather yield necessities. ${ }^{6}$ By contrast with the modalist account, which leaves the source of modal truth unspecified, the constitutive treatment clarifies that essentialist truths are a matter of the nature of things. Such a nature is what determines metaphysical necessities or what makes them true. In the case of kinds, which is our focus here, this fundamental relationship between essence and necessity can be expressed by the basic bridge-principle that:

\footnotetext{
${ }^{5}$ More precisely, we can distinguish between "essential properties" and "essences" for kind-membership. " $P$ is an essential property of being an $F$ iff anything is an $F$ partly in virtue of having $P$ '. Whereas, essences qua the sum or collection of the essential properties of an instance of a kind fully determine kind-membership: ' $P$ is the essence of being an $F$ iff anything is an $F$ in virtue of having $P^{\prime}$ (cf. Devitt 2008: 345).

${ }^{6}$ Cf. Devitt "Defending Intrinsic Biological Essentialism” (ms.)
} 
(E) If it is essential to $x$ being $F$ that it is $G$, then necessarily anything that is $F$ is $G^{7}$

The constitutive conception expressed by principle (E) may help us gain a deeper understanding of some familiar cases of kind-essentialism. Take, for example, Kripke's claim that necessarily gold has atomic number 79 (1980: 123). This suggests a more general connection between molecular structure and chemical kind-membership, such that

(P1) If a chemical substance $c$ has molecular structure $M$, then necessarily $c$ has $M$

We might well wonder what the status of (P1) is, namely how we know it. We may notice that (P1) instantiates Kripke's conditional guiding our knowledge of a posteriori necessities:

(P) If $P$, then necessarily $P(1971: 180)$

\footnotetext{
${ }^{7}$ Incidentally, for cases of individual essentialism we have a corresponding basic principle
}

$(\mathrm{E})^{i} \quad$ If $x$ is essentially $F$, then necessarily $x$ is $F$

At the sentential level, $(E)$ and $(E)^{i}$ can be expressed in a straightforward way with the Finean notation:

$(\mathrm{E})^{F} \quad \square_{\mathrm{x}} \mathrm{P} \rightarrow \square \mathrm{P}$

which reads, "If a proposition $\mathrm{P}$ is true in virtue of the essence of $\mathrm{x}, \mathrm{P}$ is metaphysically necessary"; where " $x$ ", depending on the cases, stands for either an individual or a kind (I here leave out some complications discussed in Fine 1994b). See also Vaidya and Wallner (ms.), cit.

It is important to stress that there is no direct entailment from (E) to the distinct thesis of Essential Membership: i.e., the doctrine that if an individual belongs to a kind it does so essentially (in Devitt's terminology, "Individual Essentialism in Biology" ms.). According to Essential Membership, an individual $I$ is essentially a member of kind $K$ iff its having $E i$ (a certain individual essence) entails its having $E k$ (a certain kind-essence). So for example, a particular chunk of silver, call it Chunk, would essentially belong to the kind silver because having atomic number 47 is part of its individual essence. But that is not obvious. Granted that having atomic number 47 is essential to being an instance of silver, it is not clear that Chunk would stop existing altogether, i.e., it would go out of existence as an individual, were it somehow to lose or change its subatomic structure. A further nice example that I heard from David Papineau is a lead statue that turns into silver (imagine a conceptual artist making one). Arguably, the statue qua that very individual would still exist, though its kind-membership would have changed, from being a sample of lead to one of silver. Here I do not commit to non-conditional individual essences, but only to the relatively uncontroversial principle $(\mathrm{E})^{i}$. The intended moral is that knowledge of individual essence still requires careful investigation (but see Godman, Mallozzi, and Papineau (ms.), cit. for further discussion. I thank an anonymous referee for suggesting the Chunk case and pushing me on this point). 
Because of that, a natural thought is that (P1) is itself something that we know "by a priori philosophical analysis", as Kripke remarked (ivi). But how can that be right, given that it took scientific investigation to find out about molecular structure?

The answer is that (P1) follows from our overarching principle (E), together with an empirical premise saying that

(C) Having molecular structure $M$ is essential to being a certain kind of substance $c$

In fact, especially in the case of natural kinds, we typically discover the essence of a kind empirically, as the result of scientific investigation. Thus, although Kripke did not say this explicitly, from his analysis we can take " $P$ " to generally stand for some claim about a feature that we know to be essential via empirical investigation. In the case of kinds, the thesis is that instances of the original Kripke's conditional $(\mathrm{P})$ are true when an instance substitutes for " $P$ " an appropriate statement about what is essential to a certain kind. We can think of many further cases similar to (P1), which follow in an analogous way from (E), plus its own version of (C), and lead to corresponding a posteriori, necessary conclusions.

If this is correct, Kripke's analysis of a posteriori necessities involves not only the familiar epistemic thesis that we need empirical information in order to know certain necessities. It also involves an embryonic or implicit version of Fine's metaphysical thesis, namely the constitutive view of essence. More than that, Kripke's epistemic thesis holds because metaphysical necessities are grounded in the way the world is or in the nature of things; or, equivalently, because essential properties are the source of metaphysical necessity. Fine's essentialist insight completes Kripke's inferential story: the bridgeprinciples support knowledge of metaphysical necessity because they embed essential properties. Their views look thus complementary: whereas Kripke focuses on the epistemic issue, Fine leaves that open and targets the metaphysical issue. But we can combine them in one organic positive view, according to which knowledge of necessity is the joint product of essentialist knowledge and knowledge of the bridgeprinciples. ${ }^{8}$ Following the constitutive view and principle (E), "essence", "essential property", and

\footnotetext{
${ }^{8}$ I thus disagree with a certain reading of Kripke that wants him to hold a modalist conception of essence. His famous essentialist examples all appeal to properties that are distinctive of the individual or kind he considers (perhaps uniquely distinctive), in the sense that they appear to be constitutive of the very nature of the individual or kind — of its identity. Think of the "internal structure" of tigers; of the genetic material of the Queen, and her particular biological origin; think of the specific chunk of wood that this lectern is made of.
} 
"essentialist truth" are all more fundamental and more fine-grained notions than the corresponding de re modal notions, and give us a deeper understanding of metaphysical necessity — at least in the case of natural kinds.

The broader consequence for modal epistemology is that knowledge of metaphysical necessity is typically the joint product of two things: essentialist knowledge on the one hand, and knowledge of the bridge-principles on the other hand, which are themselves based on principle (E).

We might wonder how much progress we have made. For it seems that with this move we have just recast the epistemology of necessity in terms of the epistemology of essence. And we know that essences are often disparaged in the literature as elusive and mysterious, as some sort of relic of a prescientific era. I think that these criticisms are mistaken. Far from being hidden inaccessible entities, essences are rather things that we discover empirically. Actually, they are in many cases the plain object of scientific investigation, as we see most clearly in the case of natural kinds.

\section{Essences as Superexplanatory}

As anticipated, my thesis is that the essence of a kind plays a crucial explanatory role for all the instances of the kind. I should say something about natural kinds first. A very interesting fact about them is that they support many, many inductive generalizations. We can predict that unobserved members of the kind (members that are yet to be observed, members that existed in the past, or otherwise remotely physically located), will have the same many properties and behaviors that are typical of the observed members of the kind. These generalizations run along two dimensions of projectability: first, generality, that is, the projections cover all members of a kind. And, second, variety, that is, each kind supports many, many different generalizations (Khalidi 2015). Moreover, this is not only about inductive capacity, since kinds exhibit indeed a broader epistemic fertility, in the sense that they further support our scientific taxonomic and explanatory practices. We can describe and classify things as instances of a certain kind according to all their shared properties and behaviors. Crucially, we can explain all those features by appealing to kind-membership. ${ }^{9}$

\footnotetext{
${ }^{9}$ One issue that I do not address here is the ontology of kinds or what sorts of entities they are (if they are entities at all). Not only would answering this question require its own paper; but, strictly, my view does not commit me to the existence of kinds (or properties, for that matter), since I am not quantifying over them. Take principle (E): this is a schema into which one substitutes real predicates for " $F$ " and " $G$ ", which means it is committed to $F s$ but not to $F$-hood. The central thesis presented here is neutral with respect to this issue, and indeed compatible with a variety of answers (ranging from kinds being some sort of universals to being just sets).
} 
But what does such a remarkable epistemic fertility itself depend on? What explains the global success of our scientific practices involving natural kinds? The point is not just that, in order to count as scientific, empirical generalizations have to be non-arbitrary and non-accidental—namely, that there must be some sort of "nomological glue" that makes them more than correlations. The point is, rather, that there appear to be something which supports, at bottom, a great abundance and variety of generalizations that is uniquely distinctive of natural kinds. There is a reason why all the members of a kind share so many properties and behaviors. It would be indeed a weird huge coincidence if no such reason existed. ${ }^{10}$

The answer is that there must be a common ground. There is a common cause-an underlying property, set of properties, or a mechanism — which explains all such occurrences. It is not a baffling massive coincidence, in other words, that all those properties and behaviors constantly co-occur in certain entities in nature. The causal ground determines kind-membership, and supports the whole range of projectible, lawful patterns and counterfactual dependencies that feature in the relevant scientific generalizations. More broadly, it explains the unique epistemic fertility of natural kinds. ${ }^{11}$ In this light, natural kinds realize a distinctive fit or accommodation between our scientific epistemic practices on the one hand, and the causal structure of the world on the other hand (Boyd 1999a: 69). We may further note that this aptness to fit the aims of science, particularly its search for structural explanations, may well be part of what makes a natural kind "natural". "Naturalness" might thus be thought of largely as a matter of possessing such unifying causal properties or mechanisms. Science is especially aimed at disclosing the causal structure of the world, and natural kinds exhibit such a causal structure — or "nature's joints" in the metaphysician's idiom. Accordingly, "scientific kinds" might be a better term choice than "natural kinds". ${ }^{12}$

The idea that natural kinds are causally grounded in this way has been circulating in the philosophy of science for quite a long time, sometimes under the name of "causal ground hypothesis" for

\footnotetext{
${ }^{10}$ Similarly, Devitt (2008); Millikan (1999), (2000); Papineau (1993), (2010).

${ }^{11}$ The causal structure of a natural kind might not be as simple as I am picturing it here. For Khalidi (2015), natural kinds are defined by multiple networks of causal properties. Causal relationships might thus not be strictly "horizontal" and "one-to-many" as I sketched them. Instead, the properties of a kind would be organized hierarchically and in web-like causal structures. Khalidi thinks that such a "hierarchy or series of cascading layers of properties" characterizes especially chemical elements. Still, his picture is consistent with the thesis that there is a single essential core or mechanism, which grounds the whole causal network and to which the various multiple relationships could be ultimately traced back.

${ }^{12}$ For a recent criticism of the idea that natural kinds depend on a core causal ground, see e.g. Slater (2015), who argues that natural kinds, although they may in fact be causally grounded, should be nonetheless defined in terms of the stability and cohesiveness of "cliquish" clusters of (superficial) properties. For a response to Slater, see Lemeire: "The Causal Structure of Natural Kinds" (ms.)
} 
natural kinds (Boyd 1980, 1991, 1999a, 1999b; Craver 2009; Khalidi 2013, 2015; Millikan 1999, 2000; Wilson 1999). The crucial point for our purposes is that this causally and explanatory powerful core is what I call the "essence" of the kind, and thus what constitutes the fundamental nature of the kind.

Let us consider silver again, i.e., the element with atomic number 47. Having atomic number 47 is the essence of silver because the specific number of protons (and subatomic configuration) in the nucleus of a sample of silver is what causes, given opportune environmental conditions, the many chemical and physical properties and behaviors typically shared by all those instances (e.g. melting and boiling point, electrical and thermal conductivity, disposition to combine chemically, tensile strength, color, and odor). Accordingly, having atomic number 47 also explains all those properties and behaviors that typically characterize silver. Silver is an extremely soft and malleable white, shiny metal. It actually exhibits the highest reflectivity and electrical and thermal conductivity of any metal. It is also rather unreactive, and resistant to corrosion. All those properties shared by all samples of silver qua instances of that element are caused and explained by its unique atomic number and subatomic structure, as reported on the periodic table. And that is why I call it the "essence" of silver: for having atomic number 47 is what actually plays those core causal-explanatory roles for all the instances of silver.

The causal-explanatory account thus gives us a grip on the nature of silver, or what is about silver that determines, together with the environment, the typical features of all its instances. ${ }^{13}$ Some of those properties are also shared with other chemical elements qua members of the same chemical group. For example, other elements in group 11, to which silver belongs, like gold and copper, have a number of properties in common with silver qua members of that group. In particular, they also are highly lightreflecting metals, as well as excellent conductors of electricity and heat. We can think of chemical groups as higher chemical kinds; and themselves, in turn as included in even "higher" categories, such as metals, non-metals, and quasi-metals. Similarly, elements belonging to a certain chemical group share all the properties they do in virtue of certain common features of their subatomic structure, which causes and explains the occurrence of all the properties and behaviors typical of the group. Accordingly, we may distinguish essential properties that are uniquely identifying for being an instance of a certain element, from the essential properties that are tied to group-membership, and thus may be possessed by different

\footnotetext{
${ }^{13}$ Strevens (2014) suggests that we think of kinds as "entangled" with such underlying core properties or causal mechanisms. Being an instance of silver, in Strevens' picture, is thus more precisely a concomitant cause of all the properties and behaviors shared by all instances of silver. All $F s$ are Gs because $F_{S}$ are entangled with an underlying core $C$, which in turn is causally responsible for all the occurrences of $G$ in all the instances of $F$. Strevens' analysis has the advantage of clarifying that being an instance of e.g. silver strictly doesn't cause anything; and to allow for exceptions to the relevant causal generalizations.
} 
elements. But just as the former are necessary to being an instance of a certain element, so are the latter for certain elements to be members of a certain group.

By contrast, it is merely contingent that silver is white and lustrous. Being so shiny plays no causal and explanatory role for the many, many other properties typically shared by all instances of silver; which is to say, being white and lustrous is not essential to being an instance of silver. Silver's being shiny is rather one of the many properties that, in the right conditions, are caused and explained by a set of underlying core properties possessed by silver — specifically, by its distinctive atomic number. ${ }^{14}$

By generalization from the element case, we can then conjecture that an analogous story is available in a whole range of cases, including not only other chemical elements as well as compounds, and minerals and stones; but also stars and planets, and perhaps also fundamental physical kinds, like massive objects. The substantive hypothesis is thus that something is an instance of a certain kind in virtue of a core of structural properties, or a mechanism, which, given opportune environmental conditions, causes and explains the many superficial properties and behaviors that are typically exhibited by all instances of that kind. If this is correct, there may be a scientifically grounded way to clarify in what sense essential properties constitute the "nature" of those kinds. When we talk, in a Finean fashion, of the "nature" of a kind, what we are pointing to is this causally and explanatorily powerful underlying core of properties, or mechanism.

Importantly, like in all causal explanations, a number of other factors will be relevant to fully explain certain effects, e.g., contingent local environmental factors, but also the relevant laws of nature, and other broad background conditions, depending on the case. Ideally, one should be able to lay out the details of the whole causal structure underlying a certain effect. These are the sorts of "opportune environmental conditions", mentioned above, which have to obtain in order for essential properties, or mechanisms, to produce their typical effects. Essential properties and mechanisms should always be understood as operating together with the environment, as well as the relevant laws of nature; and full structural explanations will ideally mention all the relevant surrounding factors. Take silver again. Its being white and lustrous is largely a consequence of a variety of metaphysically contingent nomological and environmental conditions, including e.g. the particular intensity and frequency of a certain range of

\footnotetext{
${ }^{14}$ Perhaps the story may be further complicated by adding that mass number (which equals the number of protons plus neutrons) also plays a role in the occurrence of the typical chemical properties and behaviors of elements. But note that the neutron number per se has only a slight influence on chemical behavior, which argues that the atomic number is after all the main feature responsible for the resulting properties.
} 
wavelengths on Earth; the laws governing reflection as well as the nature of electromagnetic radiation; not to mention the particular features of the human eye and brain. It is plausible to think that had any of those conditions been different, silver might have been blue and dull, say, even if its atomic number were the same. ${ }^{15}$

In order for silver to be necessarily white and lustrous, some form of nomological necessitarianism would have to hold, according to which the laws of nature are metaphysically necessary (and perhaps also the relevant local environmental conditions would have to be stable across worlds). For example, if dispositional essentialism is right, properties have their identities fixed by their causal roles, that is, they are identified by dispositional essences. ${ }^{16}$ This in turn accounts for the laws of nature, which are taken to be a result of those causal behaviors. Laws spring from within the properties themselves, as opposed to being imposed, so to say, from without, whether by nature or by God. By being tied in such a way to the essence or identity of properties, the laws are themselves metaphysically necessary. Although fully compatible with nomological necessitarianism, and dispositional essentialism in particular, my account is neutral on the issue of the modal status of the laws of nature.

Also importantly, the underlying essential cores belonging to the kinds we have looked at so far are typically intrinsic, in the sense that they are independent of the relative location in time and space of the members of the kinds. Put otherwise, those sorts of kinds seem to be characterized by stable, unchanging underlying structures. Ruth Millikan categorizes them accordingly as "eternal" kinds.

Chemical, physical, and astrophysical kinds are for her all examples of eternal kinds, having a distinctive underlying core of structural properties, or a mechanism, with just the sort of causal and explanatory powers that I am describing. She calls such a core the "ontological ground of induction" (1999: 50). ${ }^{17}$

\footnotetext{
${ }^{15}$ Contra Elder (2004). According to Elder, essential properties rather come in clusters held together by virtue of the laws of nature. All that matters for the existence of a kind is that "in combination they ensure, by virtue of the laws of nature, a package found in no other natural kind" (27). There appears to be no real distinction between the essential or underlying properties of a kind, and the accidental, often superficial, properties of the kind. All the properties possessed by an instance of a kind seem indeed essential to being an instance of the kind. Couldn't silver have had a different melting point, say, if certain laws of nature happened to be different? Elder's answer is that this would not have been silver-even if it still had atomic number 47 (39-41). ${ }^{16}$ See esp. Bird (2007) and Ellis (2001). See also Swoyer's seminal paper (1982).

${ }^{17}$ By contrast, for Millikan biological kinds are rather historical kinds, in that they are identified by their histories (1999). Similarly, Godman and Papineau (forthcoming), and the above-mentioned Godman, Mallozzi, and Papineau (ms.), where we hold that copying mechanisms from common ancestors play the relevant superexplanatory roles for biological species. Note that Devitt (2008), forthcoming, "Defending Intrinsic Biological Essentialism" (ms.) cit., and "Individual Essentialism in Biology" (ms.) cit., also defends a version of biological essentialism where essences have crucial causal-explanatory roles. In his view, essences are partly relational and historical, and partly intrinsic (largely genetic).
} 
Although in the case of chemical elements we can individuate their essence with a good approximation at the level of the subatomic particles, it is of course sometimes not easy to pin down exactly which properties or mechanisms do the relevant causal work. This should not be taken to undermine the essentialist picture, however. Often times we just do not know yet what the essence isscience progressively discloses the causal structure of the world. But even if such properties and mechanisms were in principle unobservable, that would still not affect the main point that structural explanations concerning all the properties shared by the instances of a kind appear to depend on an underlying causal ground that characterizes the kind (cf. Strevens 2014; Devitt 2008; Boyd 1980). ${ }^{18}$

\section{Defending the Causal and Explanatory Powers of Essence}

I think that many metaphysical necessities can be understood by applying this causal-explanatory notion of essence. This casts important light not just, of course, on what essences are, which is an important task per se; but also crucially on the source of metaphysical necessity, namely what grounds or determines those necessities. We have in other words a better grip on what in virtue of which a certain category of necessary truths hold or what they depend on.

Philosopher of science, especially in the Quinean tradition, are usually critical of modal notions like essence and necessity, perhaps because they are afraid that these might be too "metaphysically loaded" and ultimately unscientific. But again, this is a prejudice that we should overcome. First, in investigating the causal structure of natural kinds with the goal of disclosing their fundamental nature or ontological basis, we also at the same time disclose modal consequences. Counterfactual reasoning based on core causal features of kinds plays central role in formulating scientific generalizations; and it does involve evaluating non-actual scenarios or other possible worlds, which are not mere nomological duplicates of the actual world. Moreover, essences fall squarely within a scientific description of the world because they are simply underlying causal cores having superexplanatory character.

On the other hand, we may note a potential corresponding suspicion on the side of metaphysicians, who might raise doubts about a "naturalized" conception of essence. Particularly, some

\footnotetext{
${ }^{18}$ An analogous point could be made in response to certain criticisms of Putnam's example that water is essentially $\mathrm{H}_{2} \mathrm{O}$ (Needham 2011; Tahko 2015). I take it to be a philosophically minor issue, and one that we can disregard, whether the molecular structure of water is exactly $\mathrm{H}_{2} \mathrm{O}$, or rather something more complex. Whatever that structure or mechanism is exactly, we can identify it as what plays the relevant causal and explanatory roles for kind-membership. As Devitt puts it, the talk of certain specific essences, like $\mathrm{H}_{2} \mathrm{O}$ in the case of water, should be seen as "nothing more than a philosopher's hand wave toward the scientific facts" ("Defending Intrinsic Biological Essentialism” ms. cit.: 12, fn. 21).
} 
might find the claim that the defining features of essences are causal powers suspicious. Essence is often associated to claims of non-causal ontological dependence. As Bennett has recently put it, the received view seems to be that "causal and non-causal determination are rather different beasts" (2017: 67). In response, I shall stress again that investigating the nature of things is importantly partly a matter of trying to disclose their causal structure, especially when the inquiry concerns natural kinds. But I should also say something else. Let us take, for example, microessentialism for chemical compounds, which holds that possessing a certain molecular composition is essential to being a certain kind of chemical substance. For example, having a microstructure (to a good approximation) $\mathrm{H}_{2} \mathrm{O}$ is essential to being a sample of water. According to the non-causal analysis, the essentialist claim amounts to saying that hydrogen and oxygen atoms are "ontologically prior" to the substance water; or, according to some, that the existence of a molecule of water is "grounded" in the existence of the underlying atoms of hydrogen and oxygen.

But the causal and the non-causal form of determination, and the corresponding explanations, are not mutually exclusive. On the contrary, both analyses may capture important aspects of the nature or identity of a chemical substance, particularly the relationship between its microstructure or fundamental composition and its macrostructure or superficial properties. The non-causal or grounding analysis treats the structural properties of a substance as what in virtue of which something counts as an instance of that substance, and results in non-causal, mereological explanations concerning the deep composition of those instances. This analysis thus pursues broad conditions of existence as well as compositional truths concerning chemical substances, which have distinctive modal, necessary consequences. The causal analysis, on the other hand, also holds that the structural properties of a substance are what in virtue of which something counts as an instance of that substance; but it further tells us that those structural properties, when the conditions are right, cause the superficial properties that are shared by all the instances of that substance. This analysis thus results in causal and structural explanations, and pursues truths capturing the causal structure of natural kinds. Importantly, this, too, entails modal, necessary, truths that are tied to the nature of substances. Thus, more generally, both the causal and the non-causal analyses may count as pursuing metaphysical, essentialist explanation; and we might indeed think of putting them together in fruitful cooperation. The intra-world behavior of essential properties of natural kinds may thus be captured partly by a "horizontal" causal analysis, and partly by a "vertical" non-causal analysis, each having cross-world modal implications that are tied to the nature of the kind. Together, the 
two may lead us to develop a more complete account of the nature of such kinds. Causal and non-causal forms of determination may not be such different beasts after all. ${ }^{19}$

Turning to the explanatory power of essences - better, their superexplanatory power - this is also partly a reflection of their causal roles. The capacity of explaining so many generalizations involving the properties and behaviors of things is a central desideratum of both scientific and metaphysical inquiry. Specifically, "explanation" here should be understood as (a) fully objective or metaphysical; and (b) of central interest for both the natural sciences and metaphysics. Point (a) stresses that this type of explanation is not merely subjective or otherwise dependent on particular human interests or goals. Certain relationships between things, which are informative and explanatory when discovered, are actually "out there" in the world independently of those discoveries and our particular formulations. Those are structural explanations, as opposed to epistemic ones. Point (b) stresses that the explanations in question address crucial questions for both scientific and metaphysical inquiry, because they appeal to causal patterns in nature that are ultimately tied to what it is to be a certain (kind of) thing.

Conceiving essentialist explanation as both objective and tied to causation also helps us answer certain skeptical objections concerning kind-essentialism. Why should a certain property or set of properties of a natural kind be "elevated" above all the others? Silver has many other properties, especially extrinsic and social properties, like being used for manufacture of silverware and jewelry, or being valuable to us human beings. Why couldn't any of those properties turn out to play the relevant causal and explanatory roles for identifying the kind silver? What if the biggest overall causal-explanatory factor for being (an instance of) silver is that, say, people like to make forks out of it? And what would prevent us from taking some completely arbitrary description — say, a child's first sentence about silverto pick out the essence of silver? ${ }^{20}$

In response: first, let us not lose sight of our goal here. What we are pursuing are non-arbitrary, non-accidental conditions that explain all the properties and behaviors shared by all the instances of a kind. Children's utterances are simply not significantly related to those properties and behaviors; whereas the sort of ontological ground that I have identified as the "essence" of the kind is. For that is properly

\footnotetext{
19 This is also Bennett's stance. We can think of causal and non-causal determination as part of the same family, which she calls "building". Importantly, as she remarks, "the class of building relations — causation together with vertical building —is unified not just on the cheap, but in explanatorily useful ways" (2017: 103. My emphasis).

${ }^{20}$ Thanks to Jonathan Schaffer for raising a version of this objection. For a classic criticism of kind-essentialism centered on the idea that traditional categories like "essence" and "kind" have pragmatic, interest-dependent roles, especially in biology, see Dupré, e.g. (1993).
} 
what causes all such properties and behaviors. That is the reason why we should "elevate it" above all the other properties that characterize the kind. In the case of silver, the chemical properties and behaviors shared by all its instances are certainly not the product of people's feelings about silver. By focusing on the social properties of silver, in other words, we miss the target of clarifying what in virtue of which something is a sample of silver. Indeed, every sample of silver would have the chemical properties and behaviors it does even if there were not, or had never been, anyone around to appreciate those qualities, let alone make forks out of it.

More generally, we can certainly single out and name all sorts of kinds, as many as we please. But note, first, that what then does or does not go into the kind is not up to us. That it is rather determined by how the world is (think of a bunch of random things that we decide belong to the same kind simply because they are all from New York: say, the Empire State Building, my super Joe, the Yankees, and the delicious everything bagels). Second, things are clearly different when we turn to scientific kinds. Then it is not a matter of our frivolous classificatory intentions. Instead, there is an underlying goal of progressively discovering the causal structure of the world. To be sure, in some cases we might found out that we were wrong and a certain kind actually depended on something different than what we had initially thought. We might mistakenly identify a certain property for its essence, in other words. But note that in such cases, like the chemical elements that we have been considering so far, we would need a scientific story for why that counted as a mistake, as well as for identifying another property as the actual essence of the kind. That story could not be based on our social customs or personal feelings; it would have to invoke instead the causal structure of the kind. ${ }^{21}$

To take stock. The account I propose shares the central tenets of traditional kind-essentialism from Aristotle through Locke to Kripke, and develops them in light of the causal ground hypothesis on the one hand, and a Finean, constitutive conception of essence and modality, on the other hand. According to the hypothesis I advance, essences constitute the nature of kinds in two different respects. First, essences causally bind together all the instances of a kind, thereby they underlie the structure of the kind. Second, they determine the modal implications involving the instances of the kind - essences ground or constitutively determine metaphysical necessities involving the instances of the kind. Both capacities are part of what we refer to as the "nature" of a kind. The causal capacity may be understood as part of the intra-world behavior of essence, at any metaphysically possible world. The modal capacity is

\footnotetext{
${ }^{21}$ Thanks to Michael Devitt for helpful discussion of this point. See also Devitt (1991), esp. ch. 13.
} 
instead distinctive of the cross-world behavior of essence. Furthermore, note that the latter is in some sense "fixed" by the former: what is essential to a certain natural kind at the actual world grounds or constitutively determines what is metaphysically necessary for the instances of that kind.

In virtue of such combination of capacities, essences play a role for both scientific and metaphysical explanation, which is tied to the very nature of the kind. Furthermore, there should not be any residual question that essential properties are somewhat elusive or mysterious. They are rather ordinary and accessible properties: the properties that are, typically, of interest in science. ${ }^{22}$

\section{From Knowledge of Essence to Knowledge of Metaphysical Necessity}

I call "reductionists" those who think, like I do, that once we have a grip on the metaphysics of essence we have all the elements in place to understand our knowledge of metaphysical modality (e.g. Lowe 2012; Hale 2013). From a reductionist point of view, there is a direct route, so to say, from the epistemology of essence to the epistemology of modality. Accordingly, elucidating the metaphysics of essence further enables us to resolve both epistemologies at once. ${ }^{23}$

An immediate problem that we can put aside is how we know essential properties. We may take reductionists to have a straightforward answer, at least if they endorse the view recommended so far for the case of natural kinds. Our knowledge of essential properties in those cases is simply knowledge of the relevant structural core properties, or mechanisms, having the relevant causal and explanatory powers for all the instances of the kind, as identified by the results of the natural sciences.

However, it is important to stress that, for the reduction to go through, knowledge of essential properties is not strictly sufficient. We further need to know specific bridge-principles connecting actual

\footnotetext{
${ }^{22}$ I assume that we can generally trust the scientific knowledge that is already available to us and that we can use it to make progress in modal epistemology. Fischer (2016) raises the question how we know the scientific theories themselves, and how we can trust that our philosophical interpretations of such theories are correct. One of his worries is that some modal knowledge might be needed to assess those theories in the first place. These are crucial questions for both the epistemology of science and of metaphysics, and like Fischer, I am not aiming to answer them. Note however a crucial difference between Fischer's and my view. Fischer has a deflationary view of modal epistemology, which is based on knowledge of theories. If Fischer's view gives us modal knowledge on the cheap from non-modal theories, such as chemistry, then he needs to make sure that we never adopt a theory in virtue of modal knowledge, on pain of circularity. But no such a problem arises for my view.

${ }^{23}$ What about all the other modal knowledge that needs explaining, especially the necessities of logics and mathematics, as well as conceptual necessities and normative necessities? The crucial problem is that in those areas empirical factors do not seem to contribute to knowledge of necessity. Specifically, we do not seem to have any causally-mediated connection to their relevant objects, e.g. numbers, or sets. One might perhaps develop an analogous story for such cases of purely a priori necessities-as I call them - trying to preserve the general thesis that essences have "superexplanatory" powers. One could, for example, appeal to conceptual entailments from real definitions as the analogues of causal connections from essential properties and mechanisms. Clearly, addressing those issues adequately requires its own paper, which is why I leave it to future work. (Thanks to Paul Boghossian for pressing me on this issue).
} 
essentialist truths with their modal necessary implications ${ }^{24}$, the most basic of which is the above introduced

(E) If it is essential to $x$ being $F$ that it is $G$, then necessarily anything that is $F$ is $G$

Specifically, knowledge of metaphysical necessity proceeds inferentially from knowledge of essence, following Kripkean bridge-principles of the sort 'If a chemical element $e$ has subatomic structure $S$, then necessarily $e$ has $S^{\prime}$; where this, in turn, is supported by the overarching bridge-principle (E), plus the empirical premise stating that having a certain atomic number is essential to being a certain element. If having atomic number 47 is essential to being (an instance of) silver, then necessarily anything that is an instance of silver has atomic number $47 .^{25}$ These Kripkean bridge-principles capture the metaphysical connection between essence and necessity and support our inferences from essentialist truths to metaphysically necessary truths accordingly. In this way, they contribute to justify those inferences from knowledge of particular essential properties to knowledge of the corresponding metaphysical necessities, and provide the desired extra-component for knowledge of necessity, besides essentialist knowledge. Without such principles, our modal inferences appear unsupported. Any serious attempt at elucidating the justification of our modal beliefs thus needs to incorporate such principles.

At the most basic level, principle (E) makes clear that metaphysical necessities are grounded in essentialist facts. By explicitly embedding an essential property or set of essential properties “ $F$ ”, (E) improves Kripke's original conditional, 'If $P$, necessarily $P$ ', by clarifying what in virtue of which all the metaphysically necessary truths are true. (E) draws attention to the content of the empirical premises that feature in modal inference; and, in this way, it also sets a working framework for potential new cases and expanding on Kripke's original examples. Principle (E) thus holds at the metaphysical-constitutive level

\footnotetext{
${ }^{24}$ Compare Horvath's criticism of Lowe's account of modal knowledge (2014). Horvath crucially draws the general moral that essence-based accounts of modal knowledge need to integrate knowledge of the fundamental connection between essence and metaphysical necessity. Tahko (2016: 34-35) disagrees. For him, reductionism just follows from a Finean constitutive conception of essence. While this may be true, nonetheless I do not think that it exonerates us, for epistemological purposes, from making knowledge of that underlying connection explicit. Similarly, Vaidya and Wallner (ms.) cit.

${ }^{25}$ We can further specify two sub-principles of (E), depending on whether we are considering essential properties or essences:
}

(E) If $E$ is an essential property of being an $F$, then necessarily anything that is an $F$ has $E$

(E) If $E$ is the essence of being an $F$, then necessarily anything that has $E$ is an $F$

If, as I hold, having a certain atomic number is the essence of being an instance of a certain element, then as per (E) we should conclude that e.g. necessarily anything that has atomic number 47 is an instance of silver. 
because it expresses the fundamental relationship between essence and metaphysical necessity. But it also holds at the epistemological-normative level because it shows how correct modal inference to metaphysical necessity goes, based on that fundamental relationship.

Moreover, (E) is a priori, as it expresses the fundamental connection between the actual and the non-actual (necessary). It is a familiar point that empirical knowledge of the actual world cannot give us access to the non-actual, which is something that structurally or by its very nature cannot be an object of empirical observation and experience. (One might draw a comparison with the analogous case of induction) ${ }^{26}$ Nonetheless, this should not throw us into deep modal skepticism. The epistemology of other important areas of knowledge where we similarly seem to lack experiential connections with their objects, primarily logic and mathematics, also requires that we resort to some form of a priori justification in order to explain how we support the relevant beliefs. ${ }^{27}$ The structural lack of experiential connection with the non-actual thus simply shows that modal knowledge is importantly partly a priori. We need an $a$ priori step of some sort (inferential, or intuition-based) to contribute to justify those beliefs that go beyond our experience of the actual world. Principle (E) supports such a step, and accordingly is itself $a$ priori. Indeed, it is analytic - on a Finean, "thick" notion of analyticity that captures truth in virtue of the very nature of the concepts involved - as (E) expresses part of what the concepts of "metaphysical necessity" and "metaphysically necessary truth" pick out. ${ }^{28}$

Finally, as anticipated, while all bridge-principles will have an a priori component by working as connectives between the actual and the non-actual realm, their conclusions will often come out $a$ posteriori, especially in the many cases involving natural kinds. This is because discovering what plays the actual causal and explanatory roles for a kind, that is its essence, is an empirical matter. We typically carry it out within scientific practice, through considerations of empirical nature, particularly inductive and abductive ones.

\footnotetext{
${ }^{26}$ For an opposite view, see e.g. Strohminger (2015), who argues that we have perceptual knowledge of possibility. Indeed, a number of authors in the literature have recently advocated a sharply empirical turn in modal epistemology, often with the goal of eschewing traditional a priori means for knowledge of metaphysical modality (e.g. Bueno and Shalkowski 2015; Fischer and Leon 2017; Vetter 2016). But note also that there has already been an opposite push-back (see Mallozzi: forthcoming).

${ }^{27}$ Cf. the classic Benacerraf(1973).

${ }^{28}$ A further option could be that the principle is neither strictly a priori nor a posteriori. The friend of Williamson's views would claim that its justification is perhaps "armchair", as it seemingly straddles our ordinary epistemological categories (Williamson 2007, 2013).
} 


\section{Conclusion}

I argued that knowledge of metaphysical necessities involving natural kinds is the product of essentialist knowledge concerning those kinds, together with knowledge of certain Kripkean conditionals that instantiate a basic modal bridge-principle. We discover (most) essential properties a posteriori, via scientific investigation aimed at disclosing the causal structure of kinds; while the particular Kripkean conditionals all involve an a priori inferential component. This approach to the epistemology of metaphysical modality puts metaphysics first and, specifically, essence first. Thus, we should focus on investigating the properties that constitute the nature of things, namely the essential properties, as well as the metaphysical principles that structure modal reality, namely the Kripkean essentialist bridgeprinciples. In the background of the project is the idea that metaphysical modal inquiry is an empirically informed inquiry into what is possible and necessary for the things of our world, given their nature. T. E. Wilkerson nicely pointed out that natural kinds "lend themselves to science" (1988: 29). As it turns out, the essences of natural kinds lend themselves to us through science. The epistemology of metaphysical modality thus proceeds, via the epistemology of essence, hand in hand with scientific investigation. ${ }^{29}$

\footnotetext{
${ }^{29}$ I am grateful to Paul Boghossian, Michael Devitt, Boris Kment, David Papineau, Andrea Raimondi, Jonathan Schaffer, Tuomas Tahko, Anand Vaidya, Michael Wallner, and two anonymous referees for useful comments on earlier drafts of this paper. Thanks also to audiences at the Saul Kripke Center in March 2017, at the Conceivability \& Modality conference in Rome in June 2017, and at the Pacific Meeting of the APA in San Diego in March 2018.
} 


\section{References}

Bealer, G. (2002): Modal Epistemology and the Rationalist Renaissance, in Gendler, T. and Hawthorne, J. (eds.), Conceivability and Possibility, Oxford: Oxford University Press: 71-125.

Benacerraf, P. (1973): Mathematical Truth, Journal of Philosophy 70: 661-679.

Bennett, K. (2017): Making Things Up, Oxford: Oxford University Press.

Bird, A. (2007): Nature's Metaphysics, Oxford: Oxford University Press.

BonJour, L. (1998): In Defense of Pure Reason, Cambridge: Cambridge University Press.

Boyd, R. (1980): Scientific realism and naturalistic epistemology, in PSA: Proceedings of the biennial meeting of the Philosophy of Science Association, Chicago: Philosophy of Science Association: 613-662.

. (1991): Realism, Anti-Foundationalism, and the Enthusiasm for Natural Kinds, Philosophical

Studies 61: 127-148.

. (1999)a: Kinds, Complexity and Multiple Realization. Philosophical Studies, 95, 67-98.

. (1999)b: Homeostasis, Species, and Higher Taxa. In Wilson, R.A. (Ed.), Species: New

Interdisciplinary Essays, Cambridge, MA: MIT Press: 141-185.

Bueno, O. and Shalkowski, S. (2015): Modalism and Theoretical Virtues: Toward an Epistemology of Modality, Philosophical Studies 172: 671-89.

Chalmers, D. (2002): Does Conceivability Entail Possibility?, in Gendler, T. and Hawthorne, J. (eds.), Conceivability and Possibility, Oxford: Oxford University Press: 145-201.

Copi, I. (1954): Essence and Accident, Journal of Philosophy 51: 706-719.

Chudnoff, E. (2013): Intuitions, Oxford: Clarendon Press.

Craver, C. (2009): Mechanisms and Natural Kinds, Philosophical Psychology 22: 575-594

Devitt, M. (1991): Realism and Truth, $2^{\text {nd }}$ ed., Princeton, Princeton University Press. . (2008): Resurrecting Biological Essentialism, Philosophy of Science 75: 344-382.

. (forthcoming): Historical Biological Essentialism, Studies in History and Philosophy of Biological and Biomedical Sciences.

Dupré, J. (1993): The Disorder of Things: Metaphysical Foundations of the Disunity of Science, Cambridge MA, Harvard University Press.

Ellis, B. (2001): Scientific Essentialism, Cambridge: Cambridge University Press.

Fine, K. (1994)a: Essence and Modality, Philosophical Perspectives 8: 1-16. 
. (1994)b: Senses of Essence, in Sinnott-Armstrong, W., Raffman D., \& Asher, N. (eds.), Modality,

Morality and Belief. Essays in Honor of Ruth Barcan Marcus, Cambridge University Press: 53-

73.

. (2005): Modality and Tense: Philosophical Papers, Oxford: Oxford University Press.

Fischer, B. (2016): A theory-based epistemology of modality, Canadian Journal of Philosophy 46: 228247.

Fischer, B. and Leon, F. (eds.) (2017): Modal Epistemology After Rationalism, Synthese Library, Springer.

Godman, M. \& Papineau, D. (forthcoming): Species Have Historical not Intrinsic Essences, in A. Bianchi (ed.): Language and Reality From a Naturalistic Perspective: Themes From Michael Devitt, Springer Editions.

Hale, B. (2018): Essence and Definition by Abstraction, Synthese: 1-17: https://doi.org/10.1007/s11229$\underline{018-1726-7}$

. (2013): Necessary Beings, An Essay on Ontology, Modality, and the Relations Between Them, Oxford: Oxford University Press.

Horvath, J. (2014): Lowe on Modal Knowledge, Thought 3: 208-217.

Ichikawa, J. \& Jarvis, B. (2011): Rational Imagination and Modal Knowledge, Nous: 1-32.

Khalidi, M. (2015): Natural Kinds as Nodes in Causal Networks, Synthese: 1-18.

. (2013): Natural Categories and Human Kinds, Cambridge: Cambridge University Press.

Kment, B. (2014): Modality and Explanatory Reasoning, Oxford: Oxford University Press.

Kripke, S. (1980): Naming and Necessity, Oxford: Blackwell.

Kung, P. (2010): Imagining As a Guide to Possibility, Philosophy and Phenomenological Research 81: 620-663.

Lowe, E.J. (2012): What is the Source of our Knowledge of Modal Truths, Mind, 121: 919-950.

Mallozzi, A. (2018): Two Notions of Metaphysical Modality, Synthese: 1-22: https://doi.org/10.1007/s11229-018-1702-2 . (forthcoming): New Directions in the Epistemology of Modality, special issue of Synthese.

Menzies, P. (1998): Possibility and Conceivability: A Response-Dependent Account of Their Connections, in Casati, R. (ed.), European Review of Philosophy 3: 255-277.

Millikan, R. (1999): Historical Kinds and the "Special Sciences", Philosophical Studies 95: 45-65. 
_. (2000): On Clear and Confused Ideas: An Essay about Substance Concepts, Cambridge: Cambridge University Press.

Needham, P. (2011): Microessentialism: What is the Argument?, Nô̂s 45: 1-21.

Oderberg, D. (2007): Real Essentialism, New York: Routledge.

Papineau, D. (1993): Philosophical Naturalism, Oxford: Blackwell.

. (2010): Can Any Sciences be Special?, in Macdonald, C. and Macdonald, G. (eds.), Emergence in Mind, Oxford: Oxford University Press.

Peacocke, C. (1999): Being Known, Oxford, Oxford University Press.

Roca-Royes, S. (2016): Similarity and Possibility: An Epistemology of De Re Possibility for Concrete Entities. in Fischer and Leon (eds.): Modal Epistemology After Rationalism, Synthese Library, Springer: $247-262$.

Sidelle, A. (1989): Necessity, Essence, and Individuation, Ithaca: Cornell University Press.

Slater, M. (2015): Natural Kindness, British Journal for the Philosophy of Science 2: 375-411.

Strevens, M. (2014): High-Level Exceptions Explained, Erkenntnis 79: 1819-1832.

Strohminger, M. (2015): Perceptual Knowledge of Nonactual Possibilities, Philosophical Perspectives, 29: $363-375$.

Swoyer, C. (1982): The Nature of Natural Laws, Australasian Journal of Philosophy 60: 203-223.

Tahko, T. (2015): Natural Kind Essentialism Revisited, Mind 124: 795-822.

. (2016): Empirically-Informed Modal Rationalism, in Fischer and Leon (eds.): Modal Epistemology

After Rationalism, Synthese Library, Springer: 29-46.

. (forthcoming): The Epistemology of Essence, in A. Carruth, S. C. Gibb \& J. Heil (eds.), Ontology,

Modality, Mind: Themes from the Metaphysics of E. J. Lowe. Oxford University Press.

Thomasson, A. (2007): Modal Normativism and the Methods of Metaphysics, Philosophical Topics 35:

$135-160$.

Vaidya, A. (2008): Modal Rationalism and Modal Monism, Erkenntnis 68: 191-212.

. (2017): Modal Knowledge: Beyond Rationalism and Empiricism, in Fischer and Leon (eds.): Modal

Epistemology After Rationalism, Synthese Library, Springer: 85-114.

Vetter, B. (2016): Williamsonian Modal Epistemology, Possibility-Based, Canadian Journal of

Philosophy 46: 766-795.

Wilkerson, T.E. (1988): Natural Kinds, Philosophy 63: 19-42.

Williamson, T. (2007): The Philosophy of Philosophy, Oxford: Blackwell. 
_. (2013): How Deep Is the Distinction Between A Priori and A Posteriori Knowledge?, in Casullo, A. \& Thurow, J. (2013): The A Priori in Philosophy, Oxford: Oxford University Press: 291-313. . (2016): Modal Science, Canadian Journal of Philosophy 46: 453-492. . (2017): Modality as a Subject for Science, Res Philosophica 94: 415-436.

Wilson, R.A. (1999): Realism, Essence, and Kind: Resuscitating Species Essentialism? in Wilson, R.A. (Ed.), Species: New Interdisciplinary Essays, Cambridge, MA: MIT Press: 187-207.

Yablo, S. (1993): Is Conceivability a Guide to Possibility?, Philosophy and Phenomenological Research 53: $1-42$. 